\title{
Bilateral cataracts and insulin oedema in a child with type 1 diabetes mellitus
}

\author{
Aruna Goturu, Neemisha Jain, Ivor Lewis
}

Department of Paediatrics, East Surrey Hospital, Redhill, UK

\section{Correspondence to} Dr Aruna Goturu, arunaphanish@btinternet.com

\section{SUMMARY}

We describe a teenage type 1 diabetic girl with painless pedal oedema and bilateral cataracts. She developed oedema after commencement of intensive insulin therapy and achievement of excellent glycaemic control. In addition, she was also found to have bilateral subcapsular cataracts. The oedema subsided spontaneously and she underwent surgical treatment for the cataracts. Insulin oedema is a rare complication of insulin therapy. To our knowledge, co-occurrence of these two complications in a young diabetic patient has not been described before in the English language medical literature.

\section{BACKGROUND}

Oedema is a common presenting manifestation of renal, cardiac and liver diseases. This young girl presented to us with bilateral pedal oedema and visual disturbances 3 months after commencement of insulin therapy. There were no clinical or laboratory results suggestive of cardiac, hepatic or renal disease. The clinical profile was consistent with insulin oedema. It is important for the clinicians treating children with type 1 diabetes to be aware of this self-limiting potential complication of insulin therapy. In addition, the patient also had bilateral subcapsular cataracts, thus making this an unusual presentation with two uncommon complications associated with diabetes and its treatment.

\section{CASE PRESENTATION}

A 13-year-old girl was referred with a 4-month history of polyuria, polydipsia and weight loss. She was a keen dancer with a body mass index (BMI) of 12.4. She had glycosuria with blood glucose of $18.8 \mathrm{mmol} / \mathrm{l}$ and her $\mathrm{HbA} 1 \mathrm{c}$ was $16.6 \%$ $(157.9 \mathrm{mmol} / \mathrm{mol})$. She was not in diabetic ketoacidosis. Antiglutamic acid decarboxylase antibody level was $815 \mathrm{U} / \mathrm{ml}$ (normal range $0-1$ ). A diagnosis of type 1 diabetes mellitus was made.

There was no history of type 1 diabetes mellitus or autoimmune diseases in the family. She was managed on multiple subcutaneous insulin injections per day, NovoRapid insulin with meals and insulin glargine (Lantus) once a day. She was followed up regularly. Her initial insulin requirement was 0.6 units $/ \mathrm{kg} /$ day. Two weeks after diagnosis, it was noted that she was very anxious about eating carbohydrates. She mainly ate low-carbohydrate, very low-fat and high-fibre diet. An eating disorder was suspected. However, she neither abused laxatives nor had a history of induced vomiting. She had a dietician's review and was also assessed by the Child and Adolescent Mental Health Services. She was encouraged to increase her carbohydrate intake.

Three months following the initial diagnosis, she was having a balanced diet and had gained weight. As a result of her increased carbohydrate intake, her insulin requirement had gone up to 0.76 units $/ \mathrm{kg} /$ day with excellent glycaemic control, and her HbA1c was $6.6 \%$. However, she was noted to have bilateral non-tender pitting oedema. The rest of her general physical and systemic examination was normal. Her renal, liver and thyroid function tests were normal; serum albumin was $50 \mathrm{~g} / \mathrm{l}$ with normal phosphate levels. Her urinary albumin creatinine ratio was 1 . Urinary sodium was $32 \mathrm{mmol} / \mathrm{l}$ and urinary potassium was $21 \mathrm{mmol} / \mathrm{l}$. There were no casts in the urine. Abdominal ultrasound and chest x-ray were normal.

In addition, she complained of difficulty in reading books with no previous history of visual disturbances. On ophthalmological assessment, she was found to have bilateral posterior subcapsular cataracts.

The pedal oedema disappeared after 6 weeks without any treatment. A diagnosis of insulin oedema was made as no hepatic, renal or cardiovascular cause was found.

At further review, she was noted to gain weight and the initial presumption of anorexia nervosa was proved wrong. Her BMI had increased to 17 .

She underwent bilateral cataract extractions and intraocular lens implantation. There was no evidence of diabetic retinopathy.

She was changed from multiple dose insulin injections to continuous subcutaneous insulin infusion 7 months after her diagnosis with excellent glycaemic control (see table 1).

\section{DIFFERENTIAL DIAGNOSIS}

The differential diagnoses were nephritic/nephrotic syndrome, congestive cardiac failure or chronic liver disease. These were excluded based on clinical features and investigations.

\section{TREATMENT}

She was managed on multiple subcutaneous insulin injections per day, NovoRapid insulin with meals and insulin glargine (Lantus) once a day. Her initial insulin requirement was 0.6 units $/ \mathrm{kg} /$ day. Seven months after diagnosis, she was treated with continuous insulin infusion with excellent glycaemic control.

\section{OUTCOME AND FOLLOW-UP}

The diabetes was initially managed with basal bolus insulin followed by continuous insulin pump with 
Table 1 Laboratory investigations

\begin{tabular}{lll}
\hline & $\begin{array}{l}24 / 3 / 2010 \\
\text { (At } \\
\text { diagnosis) }\end{array}$ & $\begin{array}{l}\text { 13/07/2010 (At the } \\
\text { time of development } \\
\text { of oedema and } \\
\text { cataracts) }\end{array}$ \\
\hline HbA1c & $16.6 \%$ & $6.6 \%$ \\
Glucose (mmol/l) & 18.8 & 6.5 \\
Sodium (mmol/l) & 139 & 142 \\
Potassium (mmol/l) & 5.8 & 4.3 \\
Bicarbonate (mmol/l) & 26 & 23 \\
Urea (mmol/l) & 8.4 & 5.0 \\
Creatinine ( $\mu$ mol/l) & 72 & 46 \\
Calcium (mmol/l) & 2.22 & 2.11 \\
Phosphate (mmol/l) & 1.26 & 1.59 \\
Protein (g/l) & 67 & 71 \\
Albumin (g/l) & 52 & 50 \\
Alanine transaminase (U/l) & 35 & 42 \\
Haemoglobin (g/l) & 17.3 & 15.3 \\
Wcc ( $\left.\times 10^{9} / \mathrm{l}\right)$ & 4.5 & 6.3 \\
Thyroid-stimulating hormone (mu/l) & 3.9 & 4.33 \\
T4 (pmol/l) & 13.9 & 19.9 \\
Random cortisol (nmol/l) & $\mathrm{NA}$ & 443 \\
uACR (urinary albumin creatinine ratio) & & 1 \\
(mg/mmol) & & \\
Autoantibody screen & & Negative \\
\hline
\end{tabular}

excellent glycaemic control. The oedema subsided after 6 weeks, and for cataracts she underwent bilateral extractions with intraocular lens implantation.

\section{DISCUSSION}

Oedema following the initiation of insulin therapy is known but uncommon, and the incidence of this complication in children with type 1 diabetes mellitus is not known. It was first described by Leifer ${ }^{1}$ in 1928 in an adult with diabetes. The first case of insulin oedema in a child with diabetes was described by Lawrence $^{2}$ in 1979 . Since then, 12 cases of insulin oedema in children have been reported. ${ }^{3} 4$

Oedema associated with insulin therapy is rare in children and is a self-limiting condition. Cardiac, renal and hepatic causes of oedema should be excluded before attributing the condition to insulin oedema. It has been reported that insulin oedema occurs during improved glycaemic control. ${ }^{5}$ In our patient, initial HbA1c was $16.6 \%$. Three months after diagnosis, when she presented with oedema and cataracts, she had excellent glycaemic control with HbA1c of $6.6 \%$.

There are various theories for the pathophysiology of insulin oedema. Proposed mechanisms are reduced urinary sodium excretion secondary to increased sodium absorption in the diluting segment of the distal convoluted tubule. ${ }^{6}$ This study by De Fronzo et al was the landmark study describing the antinatriuretic effect of insulin. Furthermore, the authors in this study demonstrated that the sodium retention induced by insulin occurred at physiologically relevant concentrations of insulin and was independent of the filtered load of glucose, glomerular filtration rate, renal blood flow and plasma aldosterone concentration. This would suggest a direct effect of insulin on the distal tubule in increasing sodium absorption and explains the occurrence of oedema, as in our case, during good glycaemic control.
Insulin causing an increase in vascular permeability is another possible mechanism in insulin oedema. ${ }^{7}$

As in our case, there are reports that insulin oedema resolves spontaneously without treatment. ${ }^{3}$ It is interesting to note that many children with insulin oedema have a low BMI. ${ }^{3}$

There are reports of cataracts in children who have been recently diagnosed with diabetes mellitus with a prevalence of around $1 \% .^{8}$ In our case, bilateral cataracts were detected 3 months after the initial diagnosis of diabetes mellitus, and our patient had polyuria and weight loss for 3 months prior to diagnosis. The mechanism of cataract formation in a diabetic patient is not fully known. It has been reported that long duration of diabetic symptoms prior to starting treatment may be significant in the pathogenesis of cataract. ${ }^{8}$ Ketoacidosis at the time of diagnosis could affect the lens and possibly contribute to the formation of cataract. ${ }^{8}$ However, our patient was not in diabetic ketoacidosis. High $\mathrm{HbA1c}$ has been reported in diabetic patients with cataracts. ${ }^{9}$ The proposed mechanisms for the formation of cataract in diabetic patients include the accumulation of sorbitol in the lens causing osmotic stress. ${ }^{10}$ Van Heyningen showed that lenses of rats with experimental diabetes had very high levels of sorbitol. This is because the excess glucose was reduced by aldose reductase to sorbitol within the lens. Sorbitol increased the intracellular osmolarity and drew water into the lens. This led to changes in membrane permeability causing biochemical changes contributing to cataract formation. Another suggested mechanism of cataract formation is depletion of cofactor NADPH leading to an increase in oxidative stress. ${ }^{11}$

Our patient had posterior subcapsular cataracts as described previously. ${ }^{8} 912$ The literature shows a female preponderance in diabetic cataracts. In a 16-year study conducted in Melbourne, eight out of the nine patients who had cataract were female patients. $^{12}$

In summary, we have described a rare occurrence of insulin oedema and cataracts simultaneously in a teenage diabetic girl. This could be a coincidence, or the association of cataract and oedema could suggest a generalised alteration in permeability in various tissues such as the vasculature and lens.

\section{Learning points}

- Insulin oedema is a rare complication of insulin treatment. This is often seen in patients with low body mass index upon intensification of insulin treatment and after achieving good glycaemic control.

- This diagnosis should be considered after excluding cardiac, renal and hepatic causes of oedema in a diabetic child.

- Insulin oedema is self-limiting.

- Visual impairment occurring early in a diabetic child should raise a suspicion of cataracts, and an ophthalmology opinion is recommended.

Competing interests None.

Patient consent Obtained.

Provenance and peer review Not commissioned; externally peer reviewed.

\section{REFERENCES}

1 Leifer A. A case of insulin oedema. JAMA 1928;90:610-11.

2 Lawrence JR. Diabetic (insulin) oedema. BMJ 1979;2:445. 
3 Mamoulakis D, Bitsori M, Galanakis E, et al. Insulin-induced oedema in children and adolescents. J Paediatr Child Health 2006;42:655-7.

4 Bas VN, Cetinkaya S, Agladioglu SY, et al. Insulin oedema in newly diagnosed type 1 diabetes mellitus. J Clin Res Pediatr Endocrinol 2010;2:46-8.

5 Sharon M, Cassoria FG, Rose SR, et al. Oedema associated with improved glycemic control in an adolescent with type 1 diabetes. J Paediatr 1987;111:403-4.

6 Defronzo RA, Cooke CR, Andres R, et al. The effect of insulin on renal handling of sodium, potassium, calcium, and phosphate in man. J Clin Invest 1975:55:845-55.

7 Edmonds ME, Archer AG, Watkins PJ. Ephedrine: a new treatment for diabetic neuropathic oedema. Lancet 1983:321:548-51.
8 Falck A, Laatikainen L. Diabetic cataract in children. Acta Ophthalmol Scand 1998;76:238-40.

9 Datta V, Swift PGF. Metabolic cataracts in newly diagnosed diabetes. Arc Dis Child 1997;76:118-20.

10 Van Heyningen R. Formation of polyols by the lens of the rat with sugar cataracts. Nature 1959;184:194-5.

11 Lee AY, Chung SS. Contributions of polyol pathway to oxidative stress in diabetic cataract. FASEB J 1999;13:23-30.

12 Montgomery EL, Batch JA. Cataracts in insulin-dependent diabetes mellitus: sixteen years' experience in children and adolescents. J Paediatr Child Health 1998;34:179-82.

Copyright 2013 BMJ Publishing Group. All rights reserved. For permission to reuse any of this content visit

http://group.bmj.com/group/rights-licensing/permissions.

BMJ Case Report Fellows may re-use this article for personal use and teaching without any further permission.

Become a Fellow of BMJ Case Reports today and you can:

- Submit as many cases as you like

- Enjoy fast sympathetic peer review and rapid publication of accepted articles

- Access all the published articles

- Re-use any of the published material for personal use and teaching without further permission

For information on Institutional Fellowships contact consortiasales@bmjgroup.com

Visit casereports.bmj.com for more articles like this and to become a Fellow 